\title{
PSA/IL-2/GM-CSF Vaccine
}

National Cancer Institute

\section{Source}

National Cancer Institute. PSA/IL-2/GM-CSF Vaccine. NCI Thesaurus. Code C114289.

A prostate cancer vaccine containing prostate specific antigen (PSA) combined with the cytokines, interleukin-2 (IL-2) and granulocyte macrophage-colony-stimulating factor (GM-CSF), with potential antineoplastic activity. Upon intradermal vaccination, PSA/IL2/GM-CSF vaccine may activate the immune system to induce a cytotoxic T-cell (CTL) response against prostate cancer cells expressing this antigen, thereby decreasing tumor cell growth. PSA, a glycoprotein secreted by prostatic epithelial and ductal cells, is overexpressed by prostate cancer cells. IL-2 stimulates natural killer (NK) cells and cytotoxic T-cells ag ainst the PSA-expressing tumor cells. GM-CSF promotes antigen presentation to dendritic cells and further stimulates a tumor-specific cytotoxic Tlymphocyte $(C T L)$ response. 